\title{
Wages, unemployment, and the underground economy
}

Kolm, Ann-Sofie; Larsen, Birthe

Document Version

Final published version

Publication date:

2001

License

CC BY-NC-ND

Citation for published version (APA):

Kolm, A-S., \& Larsen, B. (2001). Wages, unemployment, and the underground economy.

Link to publication in CBS Research Portal

\section{General rights}

Copyright and moral rights for the publications made accessible in the public portal are retained by the authors and/or other copyright owners and it is a condition of accessing publications that users recognise and abide by the legal requirements associated with these rights.

Take down policy

If you believe that this document breaches copyright please contact us (research.lib@cbs.dk) providing details, and we will remove access to the work immediately and investigate your claim. 


\title{
Wages, Unemployment, and the Underground Economy*
}

\author{
Ann-Sofie Kolm ${ }^{\dagger}$ and Birthe Larsen ${ }^{\ddagger}$
}

February 16, 2001

\begin{abstract}
While examining the macroeconomic effects of increased government control of the informal sector, this paper develops a two-sector general equilibrium model featuring matching frictions and workerfirm wage bargaining. Different goods are produced in the formal sector and the informal sector, and workers search for jobs in both sectors. We analyse the impact of higher punishment rates and a higher audit rate on labor market performance, and we find that a higher punishment rate (i) reduces the size of the informal sector and increases the size of the formal sector, (ii) decreases real producer wages in both sectors, and (iii) reduces the unemployment rate. The effect of a higher audit rate is less clear. We find that a higher audit rate (i) reduces the size of the the informal sector relative to the size of the formal sector, and (ii) has an ambiguous impact on unemployment and real wages.
\end{abstract}

JEL-codes: H26

Keywords: Tax evasion, underground economy, matching, bargaining, unemployment.

${ }^{*}$ We want to thank Peter Fredriksson, Nils Gottfries, Bertil Holmlund, Tomas Lindström, Dale Mortensen, Søren Bo Nielsen, Åsa Rosen, Lars-Erik Öller and seminar participants at Aarhus Business School, the Zeuthen Workshop 2000 at the University of Copenhagen, Copenhagen Business School, NIER in Stockholm, and Uppsala University.

${ }^{\dagger}$ Department of Economics, Uppsala University, Box 513, S-751 20 Uppsala, and Office of Labour Market Policy Evaluation (IFAU), Box 513, S-751 20 Uppsala. Ph. +46 18471 1131, Fax +46 18471 1478. E-mail address: ann-sofie.kolm@nek.uu.se

${ }^{\ddagger}$ Centre for Research in Social Integration and Marginalization (CIM) and Copenhagen Business School, Department of Economics, Solbjerg Plads 3, DK-2000 Copenhagen F. Ph. +45 381525 44, E-mail address: bl.eco@cbs.dk 


\section{Introduction}

The last couple of years have witnessed a surge of academic as well as journalistic writings on the underground economy. ${ }^{1}$ One reason for this interest is that the incapability of the government to tax some sectors of the economy creates various distortions in the behaviour of economic agents. A large amount of work in the informal sector will, Ceteris paribus, reduce the tax base, and for a given revenue it implies an increase in taxes for formal sector workers. Higher taxes, in turn, may result in a further increase in the amount of informal sector work. A spiral may emerge with higher taxes and a larger informal sector.

The informal sector is of significant size in both North and South Europe, although we do see some variation. In Southern Europe, informal sector work amounts to 17-18 percent of GDP (Spain and Italy, see Ahn and De la Rica (1997) and Siesto (1992)), whereas it comes to 2-6 percent of GDP in the Nordic Countries (Pedersen and Smith (1998)). ${ }^{2}$

Early theoretical contributions of tax evasion are provided by Allingham and Sandmo (1972) and Srinivasan (1973), where underreporting of income is modeled as a decision made under uncertainty. Since these early contributions, a number of papers have enhanced the basic model of individual behaviour by, for example, incorporating endogenous labour supply decisions. ${ }^{3}$ Also general equilibrium models with tax evasion have been developed (see for example Cremer and Gahvari (1993)).

Although there has been a recent explosion of the literature on tax evasion and tax avoidance, the research is mainly carried out within the public finance tradition. In this literature wages are either assumed to be fixed or determined by market clearing.

The purpose of this paper is to examine the macro economic effects of taxand punishment policies. In particular, we focus on how a revenue neutral change in the government controls of the informal sector affects labour market performance. Hence, if the government were to control the underground economy more severely, either through higher punishment fees or through a more frequent auditing of informal sector workers and/or firms, what would then happen to unemployment, sector allocation, relative prices and wages? For example, would higher punishment fees or a higher audit rate lead to

\footnotetext{
${ }^{1}$ See Slemrod and Yitzhaki (2000) and Schneider and Eneste (2000) for two recent surveys of tax avoidence and tax evasion.

${ }^{2}$ These difference may be caused by cultural differences implying different moral costs of working in the informal sector. See Kolm and Larsen 2001 for a paper on this issue.

${ }^{3}$ See for example Andersen (1977) and Sandmo (1981) for early contributions of endogenous labour supply and underreporting of income.
} 
a smaller informal sector? Furthermore, what happens to the number of unemployed workers?

To that end, we develop a two-sector general equilibrium model featuring matching frictions and worker-firm wage bargains. Workers face job opportunities also in the informal sector and search for jobs in both the formal and the informal sector.

We find that increased government control of the informal sector in terms of higher punishment fees (i) increase the size of the formal sector and reduces the size of the informal sector (ii) reduces real producer wages in both sectors (iii) reduces the formal sector relative price, and (iv) reduces the unemployment rate. Considering the impact of a higher audit rate is less clear. A higher audit rate will most likely (i) reduce the size of the informal sector relative the size of the formal sector, (ii) reduce the formal sector relative price, and (iii) have an ambiguous impact on unemployment and real producer wages.

One can clarify the contribution of this paper as follows. First, we incorporate an imperfectly competitive labour market. This facilitates an analysis of how tax- and punishment policies affect wage setting and unemployment. Previous literature on tax evasion has either assumed that wages are fixed or determined by market clearing, which obviously is an inadequate framework to use when analyzing how tax evasion opportunities affect wage setting and unemployment. ${ }^{4}$ Second, we develope a two sector matching model including a goods demand side, and hence endogenously determined relative prices.

This paper is organized as follows. Section 2 describes the model and the equilibrium variables are derived. In section 3, we examine how the equilibrium variables (tightness, relative prices, real producer wages, sector allocation, and unemployment) are affected by a fully financed change in the punishment system. Finally, Section 4 concludes.

\section{The Model}

The economy consists of two sectors, a formal sector and an informal sector. Consumers perceive the goods produced in the two sectors to be different. The government audits the economy. With probability $p$ a worker-firm pair

\footnotetext{
${ }^{4}$ An exception is Chang and Lai (1996) who examine the relationship between underreporting of income and total tax revenues by taking into account the efficiency wage hypothesis. See also Kolm and Larsen (2001) who examines how increased controls of the underground economy affects wages and unemployment. Their paper, however, considers a complete segmented labour market where wage demands in the formal sector is unaffected by the underground economy.
} 
in the underground economy is detected and then has to pay a punishment fee and the match will be dissolved.

\subsection{Matching}

Workers search for jobs in both the formal and the informal sector. We assume that only unemployed workers search for jobs. This is a simplification, i.e. we do not acknowledge that the connection to the labour market given by working in the formal sector, brings about job opportunities not available while unemployed. Workers accept job offers as long as the expected payoff exceeds their reservation wage. ${ }^{5}$ We disregard any moral considerations the worker could have preventing him or her from applying for a job in the informal sector. ${ }^{6}$ The matching function is given by

$$
X=v^{1-\eta} u^{\eta}
$$

where $u$ is unemployment and $v$ is the total number of vacancies supplied by firms. The labour force is normalised to unity, whereby we interpret $u$ as the unemployment rate and $v$ as the vacancy rate. The number of vacancies supplied by the formal sector and the informal sector are $v^{j}, j=F, I$, and hence $v=v^{F}+v^{I}$. The worker's transition rates into the two sectors can be expressed as $\lambda^{F}=\beta \frac{X}{u}=\beta \theta^{1-\eta}=\beta \pi(\theta)$, and $\lambda^{I}=(1-\beta) \frac{X}{u}=$ $(1-\beta) \theta^{1-\eta}=(1-\beta) \pi(\theta)$, where $\beta=\frac{v^{F}}{v}$ is the fraction of vacancies supplied in the formal sector and $\theta=v / u$ is overall labour market tightness. The term $\pi(\theta)$ can be interpreted as the probability of a worker getting any job offer. The transition rates facing firms is equal across firms and given by $q=\frac{X}{v}=\theta^{-\eta}$. Furthermore, we define labour market tightness for the formal sector as $\theta^{F}=v^{F} / u$ and labour market tightness for the informal sector as $\theta^{I}=v^{I} / u$ where hence $\theta^{F}+\theta^{I}=\theta$.

\subsection{Workers}

Unemployed workers have the opportunity to apply for jobs in both the formal sector and the informal sector. Let $\lambda^{F}$ and $\lambda^{I}$ be interpreted as the probabilities of finding a job in the formal sector and in the informal sector,

\footnotetext{
${ }^{5}$ We focus on the non-trivial case where it is not optimal to refect job offers from one sector and wait for a job offer from the other sector in order to have an economy with both a formal- and an informal sector.

${ }^{6}$ In a companion paper, 'Moral costs, the informal sector and unemployment' (Kolm and Larsen 2001) we deal with this issue by letting moral costs be important for the relative sizes of the formal and the informal sector.
} 
respectively. The present discounted value of unemployment, $U$, employment in the formal sector, $E^{F}$, and employment in the informal sector, $E^{I}$, are given in the following flow value equations:

$$
\begin{aligned}
r U & =\lambda^{F}\left(E^{F}-U\right)+\lambda^{I}\left(E^{I}-U\right) \\
r E^{F} & =\frac{w(1-t)}{P}+s\left(U-E^{F}\right) \\
r E^{I} & =\frac{w(1-p \delta)}{P}+(s+p)\left(U-E^{I}\right),
\end{aligned}
$$

where $r$ is the exogenous discount rate, $t$ gives the income tax rate, $\delta$ captures the proportion of the evaded income a worker has to pay as a punishment fee if detected withholding the government taxes, and $p$ is the audit rate. $s$ is the exogenous separation rate. The match is dissolved when detected which implies that the separation rate in the informal sector exceeds the formal sector separation rate. The immediate income received in each state is expressed in real terms by division with the general price level, $P$. $P$ is the cost-of-living index which is linear homogenous in the two goods prices, $P^{F}$ and $P^{I}$, and can be derived from consumer preferences. ${ }^{7}$ The goods prices, and hence the general price level, is in equilibrium determined by market clearing and is taken as given by the individual firms and workers. It is of no importance for the results weather the flow value equations given in this section, and the next section, are given in real or in nominal terms.

\subsection{Firms}

The marginal productivity of a worker is $y^{j}, j=F, I$. Hiring costs are denoted $k^{j}, j=F, I$ and $q$ is interpreted as the firm's probability of finding a worker. Since the value functions for workers are expressed in real terms, we express the value functions for firms also in real terms.

Firms in the formal sector are characterized by the arbitrage equations:

$$
\begin{aligned}
r J^{F} & =\frac{P^{F}}{P} y^{F}-\frac{w^{F}(1+z)}{P}+s\left(V^{F}-J^{F}\right), \\
r V^{F} & =q\left(J^{F}-V^{F}\right)-\frac{k^{F}}{P},
\end{aligned}
$$

where $J^{F}$ is the value of having a filled job in the formal sector, $V^{F}$ is the value of an unfilled job in this sector, and the parameter $z$ is the payroll tax rate.

\footnotetext{
${ }^{7}$ Homothetic preferences are assumed which implies that all consumers face the same price index.
} 
Similarly, firms in the informal sector have $J^{I}$ and $V^{I}$ determined by:

$$
\begin{aligned}
r J^{I} & =\frac{P^{I}}{P} y^{I}-\frac{w^{I}(1+p \alpha)}{P}+(s+p)\left(V^{I}-J^{I}\right), \\
r V^{I} & =q\left(J^{I}-V^{I}\right)-\frac{k^{I}}{P}
\end{aligned}
$$

where $\alpha$ is the proportion of the evaded wages the firm has to pay as a punishment fee for cheating the government on payroll taxes when supplying informal sector jobs.

\subsection{Wages}

In the wage bargains, the firm and the worker take the market clearing prices as given. Wages, $w^{j}, j=F, I$ solve first order conditions from the Nash Bargaining Solutions with the worker's bargaining power being equal to $\gamma$ :

$$
\begin{aligned}
\frac{\gamma}{1-\gamma} \frac{1}{\phi^{F}}\left(J^{F}-V^{F}\right) & =E^{F}-U \\
\frac{\gamma}{1-\gamma} \frac{1}{\phi^{I}}\left(J^{I}-V^{I}\right) & =E^{I}-U
\end{aligned}
$$

where $\phi^{F}=\frac{1+z}{1-t}$ and $\phi^{I}=\frac{1+p \alpha}{1-p \delta}$ are the tax- and punishment wedges.

By use of equations (1)-(7) in equations (8) and (9), and assuming free entry, $V^{j}=0, j=F, I$, and symmetric conditions facing firms and workers within each sector, the relevant real producer wages are:

$$
\begin{aligned}
& \omega^{F}=\frac{w^{F}(1+z)}{P^{F}}=\gamma y^{F}\left(1+\rho\left(\theta^{F}+\frac{\theta^{I}}{\Delta}\right)\right), \\
& \omega^{I}=\frac{w^{I}(1+p \alpha)}{P^{I}}=\gamma y^{I}\left(1+\rho \Delta\left(\theta^{F}+\frac{\theta^{I}}{\Delta}\right)\right),
\end{aligned}
$$

where

$$
\Delta=\psi \frac{P^{F} y^{F}}{P^{I} y^{I}}
$$

and

$$
\psi=\frac{\phi^{I}}{\phi^{F}}=\frac{1+p \alpha}{1-p \delta} / \frac{1+z}{1-t} .
$$


where we have used that $k^{j}=\rho P^{j} y^{j}, j=F, I$. That is, we assume that hiring costs are related to the value of the marginal productivity of a worker, more resources are used to find a high productivity worker. $\psi$ is the punishment/tax wedge between the informal sector and the formal sector. We will simply refer to $\psi$ as the wedge. It seems reasonable to focus on the case when $\psi<1$, that is when the government does not audit or punish the informal sector to the same extent as the formal sector is taxed. This is, however, of no importance for the results.

The wage rules in (10) and (11) capture the wage demand, i.e., the bargained wage for a given relative price and tightness. The relative price and sector tightness are clearly endogenous variables and will be determined in equilibrium. However, before proceeding to the determination of equilibrium, we can explore the consequences of a change in the tax- and punishment rates, $\alpha, \delta, z$, and $t$, and the audit rate, $p$, on wage demands. For given equilibrium variables, an increase in the punishment rates or the audit rate for given tax rates, will reduce the formal sector wage demands, and increase the wage demands in the informal sector. The reason is that the value of employment has fallen in the informal sector relative to the formal sector. Workers employed in the informal sector hence face a reduced value of employment relative to unemployment and will push for higher wages. The opposite holds for workers employed in the formal sector, which causes formal sector workers to moderate their wage demands. Analogous interpretation can be given for changes in the tax rates for a given punishment policy.

It also follows from (10) and (11) that proportional changes in the tax and punishment system, leaving the wedge unaffected, will have no impact on wage demands since these changes have no effect on the value of employment relative to the value of unemployment in each respective sector.

\subsection{Labour market tightness}

Labour market tightness for the formal and the informal sector is determined by equations $(4),(5),(6)$ and (7) using the free entry condition and the wage equations (10) and (11) :

$$
\begin{aligned}
(r+s) \theta^{\eta} & =\frac{(1-\gamma)}{\rho}-\gamma\left(\theta^{F}+\frac{\theta^{I}}{\Delta}\right), \\
(r+s+p) \theta^{\eta} & =\frac{(1-\gamma)}{\rho}-\gamma\left(\Delta \theta^{F}+\theta^{I}\right) .
\end{aligned}
$$

Note, however, that equations (14) and (15) determine labour market tightness in the formal sector and the informal sector conditioned on the relative 
price, i.e., $\Delta=\psi \frac{P^{F} y^{F}}{P^{I} y^{I}}$. Thus we have two equations in the three unknowns, labour market tightness in the two sectors and the relative price, $\theta^{F}, \theta^{I}, \frac{P^{F}}{P^{I}}$.

Hence to close the system, we need to incorporate the product market. Before doing that it turns out to be useful to derive the employment rates.

\subsection{Employment}

Steady state employment- and unemployment rates are derived by considering the flows into and out of employment. The equations determining the employment rates $n^{F}, n^{I}$, and the unemployment rate, $u$, are given by:

$$
\begin{aligned}
\lambda^{F} u & =s^{F} n^{F}, \\
\lambda^{I} u & =s^{I} n^{I}, \\
n^{F}+n^{I} & =1-u .
\end{aligned}
$$

Solving for the employment rates and the unemployment rate, we obtain:

$$
\begin{aligned}
n^{I} & =\frac{\frac{\theta^{I}(\theta)^{-\eta}}{s+p}}{1+\frac{\theta^{F}(\theta)^{-\eta}}{s}+\frac{\theta^{I}(\theta)^{-\eta}}{s+p}}, \\
n^{F} & =\frac{\frac{\theta^{F}(\theta m)^{-\eta}}{s}}{1+\frac{\theta^{F}(\theta)^{-\eta}}{s}+\frac{\theta^{I}(\theta)^{-\eta}}{s+p}}, \\
u & =\frac{1}{1+\frac{\theta^{F}(\theta)^{-\eta}}{s}+\frac{\theta^{I}(\theta)^{-\eta}}{s+p}} .
\end{aligned}
$$

The relative sizes of the two sectors in terms of employment is therefore given by

$$
\frac{n^{F}}{n^{I}}=\frac{\theta^{F}}{\theta^{I}} \frac{s+p}{s} .
$$

\subsection{Product market equilibrium}

In each period, the product markets clear and the relative price is determined. This relative price can be derived from optimising consumers. Individuals derive utility from consumption of two goods, $C^{F}$ and $C^{I}$. $C^{F}$ is produced in the formal sector and $C^{I}$ is produced in the informal sector. Preferences 
are homothetic and captured by the following instantaneous utility function $U\left(C_{i}^{F}, C_{i}^{I}\right) .{ }^{8}$ In addition, the workers have an instantaneous budget restriction which restricts consumption of the two goods through the income allocated to consumption in each period. Let us for now assume that workers consume all their income in each period, although this is not a necessary assumption.

The consumption bundle chosen in each period by each individual is optimally determined by maximising the instantaneous utility function, given the instantaneous budget restriction. This yields the familiar condition $\frac{U_{F}\left(C_{i}^{F}, C_{i}^{I}\right)}{U_{I}\left(C_{i}^{F}, C_{i}^{I}\right)}=P^{F} / P^{I}$, which merely states that the mix of consumption goods should be chosen so that the marginal rate of substitution equals the relative price. From the individual first order conditions of choosing a utility maximising consumption mix, and the instantaneous budget restriction, we can derive each individual's demand for the two goods. With homothetic preferences, the demand for the two goods are linear in the income measure which implies that we can aggregate the demand for goods over individuals simply by aggregating over the income that restricts consumption. The aggregate demand function for the two goods are then derived by combining $\frac{U_{F}\left(C^{F}, C^{I}\right)}{U_{I}\left(C^{F}, C^{I}\right)}=P^{F} / P^{I}$ and the aggregate budget constraint. The relative price is obtained by equalising demand with supply of the two goods. The aggregate supply of the two goods (with one worker employed in each firm and the labour force normalised to unity) is given by $Y^{F}=y^{F} n^{F}$ and $Y^{I}=y^{I} n^{I}$. Equalising aggregate demand and aggregate supply leads to the following equation for the relative price

$$
\frac{U_{C^{F}}\left(\frac{y^{F} n^{F}}{y^{I} n^{I}}, 1\right)}{U_{C^{I}}\left(\frac{y^{F} n^{F}}{y^{I} n^{I}}, 1\right)}=\frac{P^{F}}{P^{I}} .
$$

For simplicity, we assume a Cobb Douglas Utility function, $U=\left(C^{F}\right)^{\sigma}\left(C^{I}\right)^{1-\sigma}$, using the Cobb Douglas assumption together with equation (19), we can rewrite equation (20) as

$$
\frac{\sigma s}{(1-\sigma)(s+p)} \frac{y^{I} \theta^{I}}{y^{F} \theta^{F}}=\frac{P^{F}}{P^{I}},
$$

\footnotetext{
${ }^{8} U_{F}, U_{F}>0$, and $U_{F F}, U_{I I}<0$. Homothetic preferences allow for aggregation of demand across individuals with different incomes, although the less restrictive assumption of quasi homothetic preferences would be enough. It is, however, convenient to have one encompassing price index for all individuals which is assured by the assumption of homothetic preferences.
} 
which is an equation in the three unknowns $\theta^{F}, \theta^{I}$, and $\frac{P^{F}}{P^{I}}$.

Note that the income level restricting consumption for consumers in each period is of no importance to the relative price, due to the assumption of homothetic preferences. Hence, it is not necessary to assume that all income is consumed in each period.

\subsection{Equilibrium}

Now we can charachterise the equilibrium in the labour and goods markets with the equations (14), (15), and (21). For simplicity, we assume that $y^{I}=y^{F}=y \cdot{ }^{9}$ We have:

$$
\begin{aligned}
(r+s)\left(\theta^{F}+\theta^{I}\right)^{\eta} & =\frac{(1-\gamma)}{\rho}-\gamma\left(\theta^{F}+\frac{\theta^{I}}{\Delta}\right), \\
(r+s+p)\left(\theta^{F}+\theta^{I}\right)^{\eta} & =\frac{(1-\gamma)}{\rho}-\gamma \Delta\left(\theta^{F}+\frac{\theta^{I}}{\Delta}\right), \\
\psi \frac{\sigma s}{(1-\sigma)(s+p)} \frac{\theta^{I}}{\theta^{F}} & =\Delta,
\end{aligned}
$$

where we recall that $\Delta=\psi \frac{P^{F}}{P^{T}}$. Firms will enter into the two sectors as long as the expected vacancy costs are equal to the discounted profit. Since the expected time to fill a vacancy $1 / q=\left(\theta^{F}+\theta^{I}\right)^{\eta}$ is equal for firms in the two sectors, the discounted profit relatively to the per period vacancy cost is going to be equal for firms in the two sectors. This is captured by equations (22) and (23). Equation (24) gives the relative price as a function of the relative supply derived from consumer preferences.

Because the separation rate for informal sector jobs is higher than the separation rate for formal sector jobs, it is more attractive for a firm to enter the formal sector since jobs on the average last a longer time in the formal sector. On the other hand if $\psi<1$, firms in the informal sector are expected to be punished less than firms in the formal sector are taxed, which makes it more attractive to enter the informal sector. However, whether it is more attractive to enter one or the other sector also depends on the prices consumers pay for the different goods produced. Or put differently, entry into one sector rather than the other sector because the relative attractiveness of the tax/punishment system or the difference in the separation rates will be counteracted by adjustments in the relative price. Entry into the formal sector will increases the supply of formal goods and hence reduce the relative

\footnotetext{
${ }^{9}$ There is no apriori reason to assume that one of the productivities should be greater than the other.
} 
price $P^{F} / P^{I}$, which in turn reduces the relative attractiveness of entering the formal sector.

We only consider fully financed reforms. Hence, the government budget restriction is always satisfied and is given by:

$$
n^{F} \omega^{F}\left(1-\frac{1}{\phi^{F}}\right)+n^{I} \omega^{I} \frac{\psi}{\Delta}\left(1-\frac{1}{\phi^{I}}\right)=\frac{R}{P^{F}} .
$$

The budget restriction is a function of the tax- and punishment wedges, $\phi^{F}$ and $\phi^{I}$, and the audit rate, $p$. Recall that the producer wages, employment rates, and $\Delta$ are functions of the wedge, $\psi=\frac{\phi^{I}}{\phi^{F}}$, and the audit rate $p$, where we note that $p$ appears both in the wedge $\psi$ and in the informal sector separation rate, $s+p$. The tax rates, $t$ and $z$ and $\delta$ and $\alpha$, will not appear in the government budget restriction directly when all substitutions are done. This reflects that $t$ and $z$ are equivalent instruments, and so are $\delta$ and $\alpha$. Hence it does not matter if we tax (punish) the firm side or the worker side. A change in $\delta$ and $\alpha$ is captured by a change in $\phi^{I}$, and a change in $z$ and $t$ is captured by a change in $\phi^{F}$.

From (25) it is clear that an increase in $\phi^{F}$ and $\phi^{I}$ that leaves $\psi$ and $p$ unaffected, will increase the government revenue. Hence for a given wedge, the government can chose $t, z, \delta$ and $\alpha$ so as to reap any level of revenue. This is very convenient and implies that we can investigate the impact of various reforms on the equilibrium variables, without explicitly incorporating the government budget restriction.

\section{Comparative statics}

This section considers the impact of two reforms on tightness, relative prices, real producer wages, sector allocation and unemployment. The first reform involves a change in the punishment rates, $\alpha$ and/or $\delta$, whereas the second reform involves a change in the audit rate $p$. Both reforms are fully financed and will be discussed in turn below.

Before considering the reforms we will engage in some substitution in order reduce the equation system in (22)-(24) and to trace down some intuition.

First, we eliminate $\left(\theta^{F}+\frac{\theta^{I}}{\Delta}\right)$ from $(22)$ and (23) above. This yields

$$
\Delta=\frac{\frac{(1-\gamma)}{\rho}-(r+s+p) \theta^{\eta}}{\frac{(1-\gamma)}{\rho}-(r+s) \theta^{\eta}}<0
$$


where $\Delta=\psi \frac{P^{F}}{P^{T}}<1$. Hence, the free entry conditions determines the relative price $\frac{P^{F}}{P^{T}}$ conditional on total tightness $\theta$. Changes in $\psi$ will induce proportional adjustments in the relative price so that $\Delta$ is unaffected.

Equation (26) reflects the discussion in connection with equations (22)(24), and verifies that it is $\psi$ and the difference in the separation rates that are important for the entry and exit into the two sectors, and hence for the relative price. This is easily seen by considering the following two imaginary polar cases. If $\psi<1$, and $p=0$, we have $\Delta=1$ and hence $\frac{P^{F}}{P^{T}}=\frac{1}{\psi}>1$. That is, the informal sector is more attractive in the sense that informal firms are expected to be punished less than formal firms are taxed. Hence firms keep entering the informal sector until the formal sector relative price has increased to such an extent that formal firms are fully compensated for the fact that $\psi<1$. If on the other hand $\psi=1$, and $p>0$, we have that $\frac{P^{F}}{P^{T}}=\Delta<1$. That is, the formal sector is more attractive in the sense that jobs on average last a longer time, and the entry of firms into the formal sector will reduce the relative price on formal goods below unity. However with $\psi<1$, and $p>0$, we have $\frac{P^{F}}{P^{T}}=\frac{\Delta}{\psi}$ which can be either smaller or larger than unity reflecting the two counteracting incentives determining the relative attractiveness of the two sectors.

Moreover, we have that

$$
\frac{\partial \Delta}{\partial \theta}=-\frac{\eta \theta^{\eta-1}(1-\gamma) p}{\rho\left(\frac{(1-\gamma)}{\rho}-(r+s)\left(\theta^{F}+\theta^{I}\right)^{\eta}\right)^{2}}<0
$$

That is, the relative price $\frac{P^{F}}{P^{I}}$ falls with an increase in total tightness for a given $\psi$ and for given separation rates. We know that $p>0$ implies that the informal sector is relatively less attractive, since jobs last on average a shorter time in the informal sector. However, when $\theta$ is low, it is quite easy to fill a vacancy. The fact that jobs separate easier in the informal sector is hence not as important since, in case of separation, the open vacancy can quickly be filled again. A large $\theta$ will, for the same reasons, increase the importance of a job lasting a substantial number of time periods. An increase in total tightness will reduce the attractiveness of the informal sector for given separation rates and $\psi$, which induces a reallocation of workers towards the formal sector with a reduction in the formal sector relative price, $\frac{P^{F}}{P^{I}}$, as a consequence.

By substituting the expression for $\Delta$ given by equation (26) into (22), we get 


$$
(r+s) \theta^{\eta}=\frac{(1-\gamma)}{\rho}-\gamma\left(\theta^{F}+\theta^{I}\left(\frac{\frac{(1-\gamma)}{\rho}-(r+s+p) \theta^{\eta}}{\frac{(1-\gamma)}{\rho}-(r+s) \theta^{\eta}}\right)^{-1}\right)
$$

where $\theta=\theta^{F}+\theta^{I}$, which is one equation in the two unknowns $\theta^{F}$, and $\theta^{I}$. We hence have a relationship between sector tightness, and most convenient this relationship is independent of the relative punishment rate, $\psi$. The relative price will adjust so to make this relationship independent of $\psi$. It will, however, depend on $p$. Differentiating (28) with respect to sector tightness and we have

$$
\frac{\partial \theta^{F}}{\partial \theta^{I}}=-\frac{(r+s) \eta \theta^{\eta-1}+\frac{\gamma}{\Delta}\left(1-\frac{\theta^{I}}{\Delta} \frac{\partial \Delta}{\partial \theta}\right)}{(r+s) \eta \theta^{\eta-1}+\frac{\gamma}{\Delta}\left(\Delta-\frac{\theta^{I}}{\Delta} \frac{\partial \Delta}{\partial \theta}\right)}<-1
$$

where $\Delta<1$. From (29), we have that informal tightness crowds out formal tightness, and vice versa. This follows because a Ceteris paribus increase in $\theta^{I}$, increases the value of unemployment, which induces a wage push also in the formal sector; formal tightness falls.

Equation (29) also reveals that a one unit increase in informal tightness will reduce formal tightness by more than one unit. This is a consequence of $\Delta$ being smaller than unity. Recall that $\Delta<1$ follows because $p>0$ prevents firms from entering the informal sector to some extent, and hence induces the relative price, $\frac{P^{F}}{P^{T}}$, to be lower than elsewise would have been the case. This price premium facing informal sector firms due to the difference in separation rates make the informal sector relatively more attractive once the match has taken place and there is bargaining over wages. This gives the informal sector a larger weight in the wage bargains in the two sectors compared to the weight given to the formal sector. An increase in informal tightness hence imposes a rather strong wage push in the two sectors. The increase in informal tightness is dampened whereas the formal tightness falls. The reduction in formal tightness does, however, induce some wage moderation, but since wage demands are not equally responsive to changes in the formal sector tightness, formal tightness falls by more than the increase in informal tightness.

\subsection{Changes in the punishment fee}

This section is concerned with the impact on tightness, relative prices, real producer wages, sector allocation, and unemployment of a fully financed 
change in the punishment fee given by a change in $\alpha$ and/or $\delta$. Tax rates $z$ and/or $t$ are adjusting so to keep the government budget in (25) balanced at all times. The audit rate $p$ is taken as given throughout this reform. As is clear from (22)-(24), (16)-(18), (10) and (11), the equilibrium variables will only be affected by changes in $\alpha, \delta, z$, and $t$ through the wedge, $\psi$. Hence, we can conduct comparative statics with respect to $\psi$ without explicitly having to account for the government budget restriction since any government revenue can be reaped by appropriate changes in $\alpha, \delta, z$, and $t$ at any given wedge.

\subsubsection{Labour market tightness and relative prices}

The effects on tightness and the relative price are summarized in the following proposition.

Proposition $1{ }^{10} A$ fully financed increase in the punishment fee, $\delta$ or $\alpha$, will increase tightness in the formal sector, $\theta^{F}$, and reduce tightness in the informal sector, $\theta^{I}$. Total tightness, $\theta$, increases. The relative price, $\frac{P^{F}}{P^{T}}$, falls.

Proof Differentiate equation (24) with respect to $\theta^{I}$ and $\psi$, taking into account that $\Delta$ is a function of $\theta^{F}$ and $\theta^{I}$ as given by (26) and that $\theta^{F}$ is a function of $\theta^{I}$ through equation (28). This yields

$$
\frac{\partial \theta^{I}}{\partial \psi}=\frac{(1-\sigma)}{\sigma} \frac{s}{s+p}\left(\frac{\partial \Delta}{\partial \theta}\left(\frac{\partial \theta^{F}}{\partial \theta^{I}}+1\right) \frac{\theta^{F}}{\theta^{I}}+\Delta \frac{\partial \frac{\theta^{F}}{\partial \theta^{I}}}{\partial}\right)^{-1}
$$

where $\frac{\partial\left(\theta^{F} / \theta^{I}\right)}{\partial \theta^{I}}=\left(\frac{\partial \theta^{F}}{\partial \theta^{I}} \theta^{I}-\theta^{F}\right) /\left(\theta^{I}\right)^{2}<0$, and $\frac{\partial \theta^{F}}{\partial \theta^{I}}+1<0$ from (29).

The equation is negative if

$-\frac{\partial \Delta}{\partial \theta}\left(\gamma \frac{\theta^{F}}{\theta^{I}}+\Delta \gamma\right) \theta^{F}-\Delta\left((r+s+p) \eta \theta^{\eta-1}+\gamma\right)-\Delta \frac{\theta^{F}}{\theta^{I}}\left((r+s+p) \eta \theta^{\eta-1}+\gamma \Delta\right)<0$

\footnotetext{
${ }^{10}$ For an intuitive intrepretation, the propositions are expressed as if an increase in $\phi^{I}$ financed by adjustments in $\phi^{F}$ implies that $\psi=\phi^{I} / \phi^{F}$ increases. Other, although perhaps less plausible cases, are of course also incorporated. The propositions simply captures fully financed changes in the tax- and punishment systems that affect the relative tax and punishment rates between the formal and informal economy.
} 


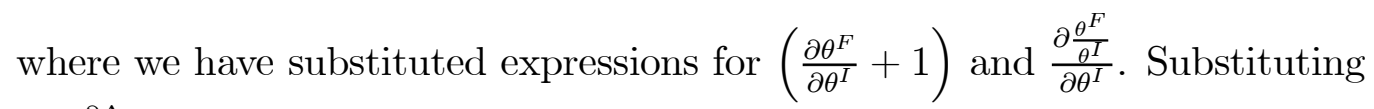
for $\frac{\partial \Delta}{\partial \theta}$ and using equation (14) we obtain the sufficient condition:

$$
(r+s+p) \eta \theta^{\eta-1}\left(\Delta \theta^{F}+\theta^{I}\right)+\Delta\left((r+s) \eta \theta^{\eta-1}+\gamma\right) \theta^{F}\left(1+\Delta \frac{\theta^{F}}{\theta^{I}}\right)>0 .
$$

Thus, $\frac{\partial \theta^{I}}{\partial \psi}<0$. Thereby $\frac{\partial \theta^{F}}{\partial \theta^{I}} \frac{\partial \theta^{I}}{\partial \psi}>0$ and $\frac{\partial \theta}{\partial \psi}=\left(\frac{\partial \theta^{F}}{\partial \theta^{I}}+1\right) \frac{\partial \theta^{I}}{\partial \psi}>0$. Regarding the relative price we have $\frac{P^{F}}{P^{I}}=\frac{\Delta}{\psi}$ where $\frac{\partial\left(\frac{P^{F}}{P}\right)}{\partial \psi}=\left(\frac{\partial \Delta}{\partial \psi} \psi-\Delta\right) / \psi^{2}<0$ since $\frac{\partial \Delta}{\partial \psi}=\frac{\partial \Delta}{\partial \theta} \frac{\partial \theta}{\partial \psi}<0$.

The smaller the difference in separation rates, the smaller is $\frac{\partial \theta^{F}}{\partial \theta^{T}}$ and, the more equal to unity is $\Delta$ and, the more perfect crowding out do we have. With perfect crowding out, i.e., $\frac{\partial \theta^{F}}{\partial \theta^{I}}=-1$, total tightness is unaffected by changes in $\psi$.

An increase in $\psi$ will make it relatively worse to be in the underground economy. Hence the value of employment in the informal sector falls relative to unemployment which increases informal sector wage demands. In the formal sector, on the other hand, wage demands fall because the value of formal employment has increased relative to unemployment. Formal sector workers thus become more keen on keeping their jobs and therefore demand lower wages.

From the firms' perspective, these happenings tend to increase the producer costs in the informal sector whereas producer costs in the formal sector tend to fall. Exit from the informal sector and entry into the formal sector are initiated. That is, labour market tightness in the formal sector, $\theta^{F}$ increases and labour market tightness in the informal sector, $\theta^{I}$ falls.

Relative prices are now affected. The reallocation of jobs towards the formal sector increases the production of formal sector produced goods relative to informal sector produced goods, which makes the price on formal goods fall relative to the price of informal goods. The relative price adjustments will eventually restore the equilibrium since the increase in the price of informal goods eventually makes it profitable to produce informal goods and hence to exit the informal sector is not profitable. For the same reason will the reduced price on formal sector produced goods eventually eliminate the profitability of entering the formal sector.

Regarding the equations for labour market tightness, the fact that $\Delta<1$ implies that the informal sector is more important for the wage bargains than is the formal sector. We show below that both wages decrease in equilibrium. The result is that total tightness increases. 


\subsubsection{Real producer wages}

The equilibrium producer wages are given by equations (10) and (11) although now we have to consider potential effects working through tightness and the relative price. We summarize the effects of changes in the tax- and punishment rates on producer wages in the following proposition:

Proposition 2 A fully financed increase in the punishment fee, $\delta$ or $\alpha$, will reduce the real producer wages, $\omega^{F}$, and $\omega^{I}$, in the two sectors.

Proof Differentiating equations (10) and (11) with respect to $\psi$ yields:

$$
\begin{aligned}
\frac{\partial \omega^{F}}{\partial \psi} & =\gamma \rho y\left(\frac{\partial \theta^{F}}{\partial \psi}+\frac{\partial \theta^{I}}{\partial \psi} \frac{1}{\Delta}-\frac{\theta^{I}}{\Delta^{2}} \frac{\partial \Delta}{\partial \theta} \frac{\partial \theta}{\partial \psi}\right) \\
\frac{\partial \omega^{I}}{\partial \psi} & =\gamma \rho y\left(\frac{\partial \theta^{F}}{\partial \psi} \Delta+\theta^{F} \frac{\partial \Delta}{\partial \theta} \frac{\partial \theta}{\partial \psi}+\frac{\partial \theta^{I}}{\partial \psi}\right) .
\end{aligned}
$$

From (14) and (15), we have:

$$
\begin{aligned}
\theta^{\eta} & =\frac{(1-\gamma)}{(r+s) \rho}-\gamma \frac{\left(\theta^{F}+\frac{\theta^{I}}{\Delta}\right)}{(r+s)}, \\
\theta^{\eta} & =\frac{(1-\gamma)}{(r+s+p) \rho}-\gamma \frac{\Delta\left(\theta^{F}+\frac{\theta^{I}}{\Delta}\right)}{(r+s+p)} .
\end{aligned}
$$

Differentiation brings out the following expressions

$$
\begin{aligned}
\eta \theta^{\eta-1} \frac{\partial \theta}{\partial \psi} & =-\frac{\gamma}{(r+s)}\left(\frac{\partial \theta^{F}}{\partial \psi}+\frac{\partial \theta^{I}}{\partial \psi} \frac{1}{\Delta}-\frac{\theta^{I}}{\Delta^{2}} \frac{\partial \Delta}{\partial \theta} \frac{\partial \theta}{\partial \psi}\right) \\
\eta \theta^{\eta-1} \frac{\partial \theta}{\partial \psi} & =-\frac{\gamma}{(r+s+p)}\left(\frac{\partial \theta^{F}}{\partial \psi} \Delta+\theta^{F} \frac{\partial \Delta}{\partial \theta} \frac{\partial \theta}{\partial \psi}+\frac{\partial \theta^{I}}{\partial \psi}\right)
\end{aligned}
$$

where we know from the proof of proposition 1 that $\frac{\partial \theta}{\partial \psi}>0$. This implies that $\frac{\partial \theta^{F}}{\partial \psi}+\frac{\partial \theta^{I}}{\partial \psi} \frac{1}{\Delta}-\frac{\theta^{I}}{\Delta^{2}} \frac{\partial \Delta}{\partial \theta} \frac{\partial \theta}{\partial \psi}<0$ and $\frac{\partial \theta^{F}}{\partial \psi} \Delta+\theta^{F} \frac{\partial \Delta}{\partial \theta} \frac{\partial \theta}{\partial \psi}+\frac{\partial \theta^{I}}{\partial \psi}<0$ have to hold. Hence we have that the equilibrium real producer wages have to fall in both sectors.

The equilibrium effects on real producer wages of changes in $\psi$ is entirely explained by changes in the reallocation of firms across sectors, $\theta^{F}$ and $\theta^{I}$, 
and effects on the total level of tightness $\theta .{ }^{11}$ We discuss the two effects in what follows.

Because $\Delta<1$, the informal sector is given a larger weight in the wage bargains than is the formal sector. Hence the wage moderation following a reduction in $\theta^{I}$ is going to be larger than the wage push following a equally sized increase in $\theta^{F}$. For a given level of total tightness, the reallocation of firms towards the formal sector will induce wage moderation in both sectors.

However, total tightness increases for exactly the same reasons. That is, there is a rather strong wage moderation induced by the reallocation of firms towards the formal sector as compared to the wage push; tightness in the formal sector tends to increase by more than tightness in the informal sector falls. (Recall the discussion below equation (27).) When total tightness increases it becomes relatively less attractive to enter the informal sector since the separation rate is higher in the informal sector than in the formal sector, which further reinforces the reallocation of firms towards the formal sector. Hence, there will be a further reduction in the relative price (that is, further reductions in the relative price than was induced in order to fully counteract the direct effects on wage demands of a change in $\psi$, see footnote 11). This tends to increase real producer wages in the formal sector and reduce the informal sector real producer wages. However, this effect can never dominate the effects induced by the fact that the reallocation brings about stronger wage moderation than wage push; real producer wages fall in both sectors.

\subsubsection{Employment}

We summarize the results on employment and unemployment in the following proposition:

Proposition 3 A fully financed increase in the punishment fee, $\delta$ or $\alpha$, will increase the employment rate in the formal sector, $n^{F}$, and reduce the employment rate in the informal sector, $n^{I}$. The unemployment rate, $u$, falls with the reform.

\footnotetext{
${ }^{11}$ The immediate effect of an increase in $\psi$ for given tightness and prices is that wage demands increase in the informal sector whereas the wage demands fall in the formal sector. This induces a reallocation of firms towards the formal sector with a reduction in formal sector relative prices as a consequence. From the previous analyses we know that $\psi$ will induce proportional adjustment in the relative price so that $\Delta$ is unaffected by changes in $\psi$ for a given level of total tightness. The direct effect of an increase in $\psi$ on wage demands is hence fully counteracted in equilbrium by relative price adjustments.
} 
Proof Differentiate equation (16) and (17) with respect to $\psi$ gives:

$$
\begin{aligned}
\frac{\partial n^{I}}{\partial \psi} & =\frac{\frac{\partial\left(\theta^{I}(\theta)^{-\eta}\right)}{\partial \psi}\left(1+\frac{\theta^{F}(\theta)^{-\eta}}{s}\right)-\frac{\theta^{I}(\theta)^{-\eta}}{s} \frac{\partial\left(\theta^{F}(\theta)^{-\eta}\right)}{\partial \psi}}{(s+p)\left(1+\frac{\theta^{F}(\theta)^{-\eta}}{s}+\frac{\theta^{I}(\theta)^{-\eta}}{s+p}\right)^{2}}<0 \\
\frac{\partial n^{F}}{\partial \psi} & =\frac{\frac{\partial\left(\theta^{F}(\theta)^{-\eta}\right)}{\partial \psi}\left(1+\frac{\theta^{I}(\theta)^{-\eta}}{s+p}\right)-\frac{\theta^{F}(\theta)^{-\eta}}{s} \frac{\partial\left(\theta^{I}(\theta)^{-\eta}\right)}{\partial \psi}}{s\left(1+\frac{\theta^{F}(\theta)^{-\eta}}{s}+\frac{\theta^{I}(\theta)^{-\eta}}{s+p}\right)^{2}}>0,
\end{aligned}
$$

where we use that

$$
\begin{aligned}
& \frac{\partial\left(\theta^{I}(\theta)^{-\eta}\right)}{\partial \psi}=\theta^{-\eta}\left(1-\eta \frac{\theta^{I}}{\theta}\left(\frac{\partial \theta^{F}}{\partial \theta^{I}}+1\right)\right) \frac{\partial \theta^{I}}{\partial \psi}<0, \\
& \frac{\partial\left(\theta^{F}(\theta)^{-\eta}\right)}{\partial \psi}=\theta^{-\eta}\left(\frac{\partial \theta^{F}}{\partial \theta^{I}}\left(1-\eta \frac{\theta^{F}}{\theta}\right)-\eta \frac{\theta^{F}}{\theta}\right) \frac{\partial \theta^{I}}{\partial \psi}>0 .
\end{aligned}
$$

Furthermore, the unemployment rate is affected in the following way:

$$
\frac{\partial u}{\partial \psi}=-\frac{\frac{s+p}{s} \frac{\partial\left(\theta^{F}(\theta)^{-\eta}\right)}{\partial \psi}+\frac{\partial\left(\theta^{I}(\theta)^{-\eta}\right)}{\partial \psi}}{\left(1+\frac{\theta^{F}(\theta)^{-\eta}}{s}+\frac{\theta^{I}(\theta)^{-\eta}}{s+p}\right)^{2}} \frac{1}{s+p} .
$$

As $\frac{s+p}{s}>1$ and $\frac{\partial \theta^{I}}{\partial \psi}<0$ a sufficient condition for $\frac{\partial u}{\partial \psi}<0$ is that

$$
\begin{aligned}
\frac{\partial \theta^{F}}{\partial \theta^{I}}\left(1-\eta \frac{\theta^{F}}{\theta}\right)-\eta \frac{\theta^{F}}{\theta}+1-\eta\left(1-\frac{\theta^{F}}{\theta}\right)\left(\frac{\partial \theta^{F}}{\partial \theta^{I}}+1\right) & <0 \Leftrightarrow \\
(1-\eta)\left(\frac{\partial \theta^{F}}{\partial \theta^{I}}+1\right) & <0,
\end{aligned}
$$

which is satisfied.

It comes as no surprise that increased punishment fees relative to tax rates induce a reallocation of workers from the informal sector towards the formal sector. An increased wedge increases the transition rate into formal sector employment, whereas the opposite movements occur in the informal sector.

The unemployment rate falls because tightness in the formal sector increases by more than tightness in the informal sector falls. The transition rate into the formal sector employment therefore tends to increase by more than the transition rate into the informal sector tends to fall. As the separation rate from the informal sector is larger than the separation rate for the formal sector, this reinforces the fact that unemployment falls with an increase in $\psi$. 


\subsection{Changes in the audit rate}

This section is concerned with the impact on tightness, relative prices, real producer wages, sector allocation, and unemployment of a fully financed change in the audit rate $p$. The tax rates $z$ and/or $t$ and the punishment fees $\alpha$ and/or $\delta$ are adjusting so as to keep the government budget in (25) balanced at all times. As is clear from (22)-(24), (16)-(18), (10) and (11), the equilibrium variables will be affected by changes in $p$ both through the wedge $\psi$, and through the informal sector separation rate, $s+p$. However, from the government budget restriction in (25) we know that there is always an appropriate adjustment in $z$ and/or $t$ and the punishment rates $\alpha$ and/or $\delta$ that will produce any level of government revenues for a given $\psi$. Hence to clarify how changes in $p$ affect the equilibrium variables via the informal sector separation rate, $s+p$, this reform considers changes in $p$ for a given $\psi$.

From the previous analysis we could conclude how changes in $\psi$ affected the equilibrium variables and it is straight forward to extent the analysis below to incorporate that $\psi$ is increased by an increase in $p$. The discussion in the introduction and in the conclusion sumarizes the full effects of an increase in $p$.

\subsubsection{Labour market tightness and relative prices}

The effects on tightness and on the relative price are summarized in the following proposition.

Proposition 4 A fully financed increase in the audit rate, $p$ (for a given $\psi$ ), will decrease total tightness, $\frac{\partial \theta}{\partial p}<0$. A sufficient condition for the relative price, $\frac{P^{F}}{P^{I}}$, to decrease, $\frac{\partial \Delta}{\partial p}<0$ is that $(s+p)(1-\eta)>\eta r$.

Proof Differentiating the equilibrium system, equations (22) - (24) give:

$$
\begin{aligned}
\frac{d \theta^{F}}{d p} & =\gamma \theta^{F} \frac{(r+s) \eta \theta^{\eta-1}\left(\Delta \theta^{F}+\frac{\theta^{I}}{\Delta} \frac{r+s+p}{r+s}-\frac{s+p}{\gamma} \theta^{\eta}\right)+\gamma\left(\theta^{F}+\frac{\theta^{I}}{\Delta}\right)}{-D} \\
\frac{d \theta^{I}}{d p} & =\gamma \theta^{F} \frac{\left(\begin{array}{c}
\eta \theta^{\eta-1}\left(\frac{p \theta^{I}}{\Delta}+(r+s)\left(\Delta \theta^{F}+\frac{\theta^{I}}{\Delta}-\frac{\theta^{\eta}(s+p)}{\gamma}\right)\right) \\
+\left(\theta^{I}+\Delta \theta^{F}\right)\left(\gamma-\frac{\theta^{\eta}(s+p)}{\theta^{F} \Delta}\right)
\end{array}\right)}{D} \\
\frac{\gamma(r+s+p) \eta \frac{1}{\theta}+(r+s) \eta \frac{1}{\theta}(1-\Delta) \gamma}{+\left((r+s) \eta \theta^{\eta-1}+\gamma\right) \frac{s+p}{\theta^{I}}} & \\
\frac{d \frac{p^{F}}{p^{I}}}{d p} & =-\frac{P^{F}}{P^{I}} \theta^{F} \theta^{\eta} \frac{+\frac{1}{\theta^{F}}(s+p)(r+s) \eta \theta^{\eta-1}+\gamma \frac{1}{\Delta}\left(\frac{s+p}{\theta^{F}}-\eta \frac{r+s+p}{\theta}\right)}{D}
\end{aligned}
$$


where

$$
\begin{aligned}
D= & (s+p) \theta^{F} \gamma\left(\frac{\theta^{F}}{\theta^{I}}\left((r+s) \eta \theta^{\eta-1}+\gamma\right) \gamma \Delta+\frac{\theta^{I}}{\theta^{F} \Delta}\left((r+s+p) \eta \theta^{\eta-1}+\gamma\right)\right. \\
& \left.+2 \gamma+(2(r+s)+p) \eta \theta^{\eta-1}\right) \\
> & 0 .
\end{aligned}
$$

Adding the derivatives for labour market tightness we obtain:

$$
\frac{d \theta}{d p}=-\gamma \theta^{F}\left(\frac{\theta^{I}}{\Delta}+\theta^{F}\right) \frac{\frac{\theta^{\eta}(s+p)}{\theta^{F}}+\gamma(1-\Delta)}{D}<0
$$

We observe that a sufficient condition for $\frac{d \frac{p^{F}}{p^{I}}}{d p}<0$ is that

$$
\left(\frac{s+p}{\theta^{F}}-\eta \frac{r+s+p}{\theta}\right) \geq 0
$$

which is true for $r \rightarrow 0$. In general, as $\theta>\theta^{F}$, we have the sufficient condition

$$
(s+p)(1-\eta)-\eta r \geq 0 .
$$

We first note that we can not exclude that informal sector tightness actually increases with an increased audit rate. An increase in $p$ reduces the profitability for firms to enter the informal sector by reducing the average length of a match, which works in the expected direction of reducing informal sector tightness. In addition, however, the relative price, $\frac{p^{F}}{p^{T}}$, is directly reduced by an increase in $p$ since the outflow of informal sector workers increases for given tightness, and hence the production of informal sector goods fall. This relative price effect will increase the attractiveness for firms to enter the informal sector, $\theta^{I}$ increases. Since we can not conclude whether $\theta^{I}$ falls or increases with $p$, we can not conclude whether $\theta^{F}$ increases or falls with $p$. The direct negative effect on the relative price tends to reduce formal sector tightness by making the formal sector less attractive for firms to enter. However, if informal sector tightness falls, formal sector tightness tend to increase since the value of unemployment is reduced and hence wages are moderated in the formal sector; $\theta^{F}$ tends to increase. The impact on $\theta^{F}$ is ambiguous.

Total labour market tightness, however, falls with an increase in the audit rate. This follows because the direct negative effect on the relative price reduces formal sector tightness. For, example, if $\theta^{I}$ increases with the reform, 
we know from (29) that $\theta^{F}$ falls by more. Hence total tightness falls. The fact that $\frac{p^{F}}{p^{I}}$ falls as a direct effect of a higher $p$, will further reduce $\theta^{F}$ and total tightness. If, on the other hand, $\theta^{I}$ falls with the reform, formal sector tightness increases by more, and total tightness tends to increase. However, the fact that the relative price falls as a direct effect of an increase in $p$ will reduce formal sector tightness, and hence the fall in $\theta^{I}$ is larger than the increase in $\theta^{F}$; total tightness falls.

In general it cannot be determined whether relative prices increase or decrease. From equation (24), we know that the direct effect of an increase in $p$ makes the relative price fall. Hence a reduction in informal sector tightness is always associated with a decrease in the relative price since then also $\theta^{I} / \theta^{F}$ falls. However, if labour market tightness in the informal sector should happen to increase, the fact that $\theta^{I} / \theta^{F}$ increases tends to increase the relative price which is counteracting the direct negative effect on the relative price.

Imposing the restriction that $(s+p)(1-\eta)-\eta r>0$, ensures that relative prices fall. For a symmetric matching function the sufficient condition may be reduced to $s>r$. Empirically we usually find that this is true. ${ }^{12}$

\subsubsection{Real producer wages}

This section is concerned with the impact of a higher audit rate on equilibrium producer wages, equations (10) and (11). We have to consider potential effects working through tightness and the relative price. The effects of a higher audit rate on producer wages is given by the following proposition:

Proposition 5 A fully financed increase in the audit rate, $p$ (for a given $\psi)$, will increase producer wages in the formal sector, $\frac{\partial \omega^{F}}{\partial p}>0$. The impact on informal sector producer wages is ambiguous. However, if the sufficient condition, $(s+p)(1-\eta)-\eta r>0$, is satisfied, then in case informal producer wages increase, they increase by less than formal producer wages increase.

Proof Differentiating equations (10) and (11) with respect to $p$ yields:

$$
\begin{aligned}
\frac{\partial \omega^{F}}{\partial p} & =\gamma \rho y\left(\frac{\partial \theta^{F}}{\partial p}+\frac{\partial \theta^{I}}{\partial p} \frac{1}{\Delta}-\frac{\theta^{I}}{\Delta^{2}} \frac{\partial \Delta}{\partial p}\right) \\
\frac{\partial \omega^{I}}{\partial p} & =\gamma \rho y\left(\frac{\partial \theta^{F}}{\partial p} \Delta+\frac{\partial \theta^{I}}{\partial p}+\theta^{F} \frac{\partial \Delta}{\partial p}\right)
\end{aligned}
$$

\footnotetext{
${ }^{12}$ See, for example, Layard et al (1991), Mortensen (1994), and Mortensen and Pissarides (1999).
} 
From (14) and (15), we have:

$$
\begin{aligned}
\theta^{\eta} & =\frac{(1-\gamma)}{(r+s) \rho}-\gamma \frac{\theta^{F}+\frac{\theta^{I}}{\Delta}}{(r+s)} \\
\theta^{\eta} & =\frac{1}{(r+s+p)}\left(\frac{(1-\gamma)}{\rho}-\gamma \Delta\left(\theta^{F}+\frac{\theta^{I}}{\Delta}\right)\right) .
\end{aligned}
$$

Differentiation brings out the following expression

$$
\begin{aligned}
\eta \theta^{\eta-1} \frac{\partial \theta}{\partial p} & =-\frac{\gamma}{(r+s)}\left(\frac{\partial \theta^{F}}{\partial p}+\frac{\partial \theta^{I}}{\partial p} \frac{1}{\Delta}-\frac{\theta^{I}}{\Delta^{2}} \frac{\partial \Delta}{\partial p}\right) \\
\eta \theta^{\eta-1} \frac{\partial \theta}{\partial p} & =-\frac{\gamma \Delta}{(r+s+p)}\left(\frac{\partial \theta^{F}}{\partial p}+\frac{\partial \theta^{I}}{\partial p} \frac{1}{\Delta}+\frac{\theta^{F}}{\Delta} \frac{\partial \Delta}{\partial p}\right)-\frac{\theta^{\eta}}{r+s+p}
\end{aligned}
$$

where we know from the proof of proposition (4) that $\frac{\partial \theta}{\partial p}<0$. This implies that $\frac{\partial \theta^{F}}{\partial p}+\frac{\partial \theta^{I}}{\partial p} \frac{1}{\Delta}-\frac{\theta^{I}}{\Delta^{2}} \frac{\partial \Delta}{\partial p}>0$, and therefore that $\frac{\partial \omega^{F}}{\partial p}>0$ and $\frac{\partial \omega^{F}}{\partial p}>\frac{\partial \omega^{I}}{\partial p}$ when $\frac{\partial \Delta}{\partial p}<0$.

Firms enter into the two sectors until the expected vacancy costs are equal to the discounted profits. This implies that the expected time it takes to fill a vacancy is equal to the discounted profits relative to the per period vacancy cost. For reasons given above, we know that total tightness fall with an increase in $p$ although we cannot determine how sector tightness and the relative prices are affected in general. If total tightness falls with the reform, and hence a vacancy is expected to be filled at a faster rate, discounted profits in the two sectors relative to per period vacancy costs has to fall as well. The reallocation of firms across the two sectors will assure that. In the formal sector this can only be achieved by an increase in the real producer wage. In the informal sector, however, an increase in $p$ will reduce the expected profits since a match is expected to last a shorter number of periods. It is hence not necessarily the case that the real producer wage in the informal sector increases as a consequence of a higher $p$.

\subsubsection{Employment}

We summarize the results on relative employment in the following proposition:

Proposition 6 A sufficient condition for the relative employment, $\frac{n^{I}}{n^{F}}$, to decrease is that $(s+p)(1-\eta)>\eta r$ following a fully financed increase in the audit rate, $p$ (for a given $\psi$ ). 
Proof Differentiate (24) with respect to $p$ and $\frac{n^{I}}{n^{F}}$ where we recall that $\frac{s}{(s+p)} \frac{\theta^{I}}{\theta^{F}}=\frac{n^{I}}{n^{F}}$ and $\frac{\Delta}{\psi}=\frac{P^{F}}{P^{I}}$ and we have $\frac{\partial \frac{n^{I}}{\partial p}}{\partial p}=\frac{\sigma}{1-\sigma} \frac{\partial \frac{P^{F}}{P I}}{\partial p}$. Hence the sign of $\frac{\partial \frac{n^{I}}{F^{F}}}{\partial p}$ is equal to the sign of $\frac{\partial \frac{P^{F}}{\partial p}}{\partial p}$. From the proof of proposition 4 we have that a sufficient condition for $\frac{\partial \frac{P^{F}}{P I}}{\partial p}<0$ is that $(s+p)(1-\eta)>\eta r$.

Relative employment $\frac{n^{I}}{n^{F}}$, and hence relative output, falls if the condition, $(s+p)(1-\eta)>\eta r$, is fulfilled. That is, the direct effect of an increase in $p$ that increases the outflow of informal employment, and hence reduces informal sector production, dominates any reallocation effects that may work in an opposite direction. See the discussion in connection to proposition 4 . It comes as no surprise that it is the same condition that restricted the relative price $\frac{P^{F}}{P^{I}}$ to fall as the relative price falls when relative output falls.

The impact on unemployment is, however, ambiguous. It is not possible to exclude the case that the unemployment rate falls with an increase in the audit rate. This is so although we know that total tightness falls, and hence the total transition rate into employment falls, and that the exit rate from the informal sector increases. ${ }^{13}$ The reason is the reallocation effect. Consider, for example, that this reforms brings about increased inflow into formal sector employment. This may reduce the unemployment rate although the transition rate into the informal sector falls by more than the transition rate into formal sector increases. This follows because the formal sector separation rate is lower than the informal sector separation rate and hence for a given increase in the sector transition rate into employment, formal sector employment has to increase by more than informal sector employment in order to balance inflows with outflow in steady state. That is, employment in the formal sector is more sensitive to changes in its transition rate than are informal sector employment.

\section{Conclusion}

This paper developed a two-sector general equilibrium matching model with different goods being produced in the formal sector and the informal sector. This enabled an analyses of how increased government control of the underground economy affects wage formation and unemployment. This is something that has been ignored in the previous literature where wages have been taken as either given or determined by market clearing. Moreover, this paper contributes to the matching literature by including more than one

\footnotetext{
${ }^{13}$ Recall that the total transition rate into employment is $\lambda^{F}+\lambda^{I}=\theta^{1-\eta}$.
} 
sector where unemployed workers search for jobs in both sectors, and the relative price is endogenously determined. This opens up the possibility for future research on, for example, how general policies affect labour market performance in an economy with sectoral differences, as well as how policies directed to sectors with specific characteristics affect labour market performance.

Based on this framework, we have shown that increased government control of the underground economy in terms of higher punishment fees (or increased auditing for given separation rates) will reduce the size of the underground economy, reduce real producer wages in the two sectors, and reduce unemployment.

Increased punishment fees induce wage demands to increase in the informal sector and fall in the formal sector. As a consequence, firms will find it profitable to exit from the informal sector and enter into the formal sector. In turn, this reallocation of production will reduce the formal sector relative price. The relative price adjustments will fully counteract the direct effects on real producer wages in equilibrium. Real producer wages and unemployment instead fall due to the rather strong wage moderation that follows this reallocation process.

The impact on real producer wages is an important but complicated process. When firms enter the formal sector, wage demands increase since employment perspectives in the formal sector increase, whereas wage demands fall when firms exit the informal sector as employment perspectives fall in this sector. The wage moderation following a firm exiting the informal sector is, however, larger than the wage push following a firm entering the formal sector. The reason is that the informal sector worker-firm pair faces an increased probability of separation due to detection. This gives the informal sector worker-firm pair a surplus to split every period in terms of a price premium. Hence, the separation of an informal match is valued more than a formation of a formal match, once the firm and worker have matched. Consequently, the wage moderation following an exit from the informal sector exceeds the wage push following an entry into the formal sector; real producer wages and unemployment falls.

Considering the full effects on labour market performance of an increase in the audit rate implied less clear results. In addition to the effects previously described, there was a direct positive effect on the probability of a workerfirm match being separated. The outflow from informal sector employment into the unemployment pool hence increased. In addition, we found that the overall transition rate into employment fell as a consequence of an increase in the informal sector separation rate. These effects tended to increase unemployment. The overall impact of increased auditing on unemployment is 
thus ambiguous. The same ambiguous effects were found considering real producer wages. We could, however, conclude that increased separation of the informal sector due to increased auditing most likely reinforced the reduction in the relative price, and that it also most likely reinforced the fact that the size of the formal sector increased relatively to the size of the informal sector.

\section{References}

[1] Ahn, Namkee and Sara de la Rica, 1997: The underground economy in Spain: an alternative to unemployment? Applied Economics 29: 733743.

[2] Andersen Per, 1977, Scandinavian Journal of Economics 79, 375-83.

[3] Allingham, Michael. G. and Sandmo, Agnar, 1972, Income tax evasion: A theoretical analysis, Journal of Public Economics 1, 323-338.

[4] Chang, Wen-Ya, and Lai, Ching-Chong, 1996, The implications of efficiency wages on tax evasion and tax collections, Public Finance Quarterly $24,163-172$.

[5] Cremer, Helmuth, and Firouz Gahvari, 1993, Tax evasion and optimal commodity taxation, Journal of Public Economics 50, 261-275.

[6] Kolm, Ann-Sofie, and Birthe Larsen, 2001, Moral costs, the informal sector and unemployment. Working paper 01-2001, Department of Economics, Copenhagen Business School.

[7] Layard Richard, Stephen Nickell and Richard Jackman, 1991, Unemployment: Macroeconomic Performance and the Labour Market, Oxford University Press.

[8] Mortensen Dale, 1994, Reducing Supply-Side Disincentives to Job Creation, in Reducing Unemployment: Current Issues and Policy Issues, Proceeding from a symposium sponsored by the Federal Reserve Bank of Kansas City.

[9] Mortensen Dale and Christopher Pissarides, 1999, New developements in Models of Search in the Labor Market, in Handbook of Labor Economics, volume 3, North Holland. 
[10] Pedersen, Søren. and Nina Smith, 1998: Sort arbejde og sort løn i Danmark.

[11] Siesto, Vincenzo, 1992: Concepts and methods involved in the last revision of Italy's GDP. Guidebook to Statistics on the hidden Economy. Conference on European Statisticians, Economic Comission for Europe, United Nations, New York.

[12] Sandmo, Agnar, 1981, Income Tax Evasion, Labour Supply, and the Equity-efficiency Trade-off, Journal of Public Economics 16, 265-88.

[13] Schneider, Friedrich, and Dominik Eneste, 2000, Shadow Economices:Size, Causes, and Consequences, Journal of Economic Literature, 38(1), 77-114.

[14] Srinivasan ,T.N.,1973, Tax Evasion, A Model, Journal of Public Economics 2, 339-346.

[15] Slemrod, Joel, and Shlomo Yitzhaki, 2000, Tax Avoidence, Evasion, and Administration, Forthcoming in Handbook of Public Economics, Working Paper, NBER:7473. 